\title{
Exercise Program in Post-Surgical Release of Knee Flexion Contracture in Patient with Osteochondroma: A Case Report
}

\author{
Deva Natalia Motik ${ }^{1 *}$, Ida Kurniawati ${ }^{2}$
}

\begin{abstract}
Introduction: Knee flexion contracture is caused by adaptive shortening of the muscles which is marked by the incapability of the knee to fully extend. This condition is associated with long periods of immobilization, pain, and muscle weakness that are caused by various pathological conditions. Post-surgical rehabilitation program is mainly aimed to recover basic lower limb functions through an exercise program.
\end{abstract}

Case description: A 16-year-old male patient with a history of left-sided knee pain and fixed flexion contracture was undergone a surgical release procedure and diagnosed with osteochondroma. Post-surgical evaluation by physical therapist found muscle

atrophy, limited range of motion, and pain on the operated limb. The patient was instructed to do muscle strengthening and active exercise on both legs. Exercise program post-surgery aimed to improve muscle strength, range of motion, functional limb ability and activities of daily living. Improvement in the range of motion of the left knee joint was observed after three sessions of physical therapy intervention.

Conclusion: Exercise program could reduce the muscle contracture and improve the knee joint range of motion in patients with osteochondroma following surgical release procedure.
'Bachelor and Professional Program of Physical Therapy, College of Medicine, Universitas Udayana

${ }^{2}$ Master Program in Graduate Institute of Biomedical Informatics, College of Medical Science and Technology, Taipei Medical University

${ }^{*}$ Corresponding author: Deva Natalia Motik; Bachelor and Professional Program of Physical Therapy, College of Medicine, Universitas Udayana; devanataliapt@gmail.com

Received : 2021-04-09 Accepted : 2021-05-03 Published: 2021-05-12

Keywords: knee flexion contracture, osteochondroma, surgical release procedure, exercise

Cite this Article: Motik, D.N., Kurniawati, I. 2021. Exercise Program in Post-Surgical Release of Knee Flexion Contracture in Patient with Osteochondroma: A Case Report. Physical Therapy Journal of Indonesia 2(1): 20-24. D0I: 10.51559/ptji.v2i1.21

\section{INTRODUCTION}

Knee flexion contracture is described as the condition of knee flexor muscles shortening and knee extension muscles deficit. The pathology of contracture refers to muscle tightness or adaptive shortening of the muscle-tendon unit and surrounding soft tissues, resulted in limited range of motion and passive or active stretch resistance. ${ }^{1}$ This condition is associated with pain and muscle weakness which is related to previous tissue injuries and long-term immobilization. ${ }^{2}$

Osteochondroma is one of benign bone tumor in form of cartilage-capped bony projection arising on the external surface of bone containing marrow cavity that grows continuously with the underlying bone as single or multiple lesions. ${ }^{3}$ Most lesions appear in painless and slow-growing masses, while the pain can appear as a result of complications such as mechanical joint problems, fracture, and vascular or neurological compromise. The affected limb can exhibit changes in color, numbness, loss of pulse, or weakness. The symptoms are often related to the size and location of the lesion, and relevant movements are often resulted in pain and restriction in joint motions. ${ }^{4}$

Osteochondroma incidence was reported as around $35 \%$ of benign and $8 \%$ of all bone tumors. Most of the cases are diagnosed within the first three decades of life, commonly in children or adolescents between 10 and 15 years of age., ${ }^{3,5}$ The complete evaluation to diagnose osteochondroma requires physical examination, X-Ray, CT, MRI, and biopsy of the lesion. Radiographic imaging is the first supporting examination that is required to represent the characteristic of the lesion.

Treatment of osteochondroma is considered based on the presence of symptoms and complications, and cosmetic reasons. The presence of symptomatic osteochondroma is one of the indications for surgical excision. The tumor needs to be completely excised in order to avoid disease recurrences. Other surgical indications are include growth retardation, limbs deformation, joint motion loss, tendons compression, or soft tissue lesions. ${ }^{4}$ Surgical release in postoperative knee contracture is a challenging procedure, but in most cases, the range of extension and flexion can be improved. ${ }^{6}$

After the surgical treatment, the patient receives a comprehensive physical therapy program, emphasizing muscle strengthening, range of motion exercise, and functional training. Physical therapy is started on postoperative day 
1 for mobilization and gait training with some postoperative restrictions, such as protected weightbearing for 6 to 12 weeks and protected range of motion. Rehabilitation program is mainly focused on improving range of motion, reducing pain, and minimizing muscle atrophy. ${ }^{6-8}$

Although osteochondroma is a common benign bone tumor, the number of reports about exercise program following contracture release surgery in osteochondroma is limited due to some unreported

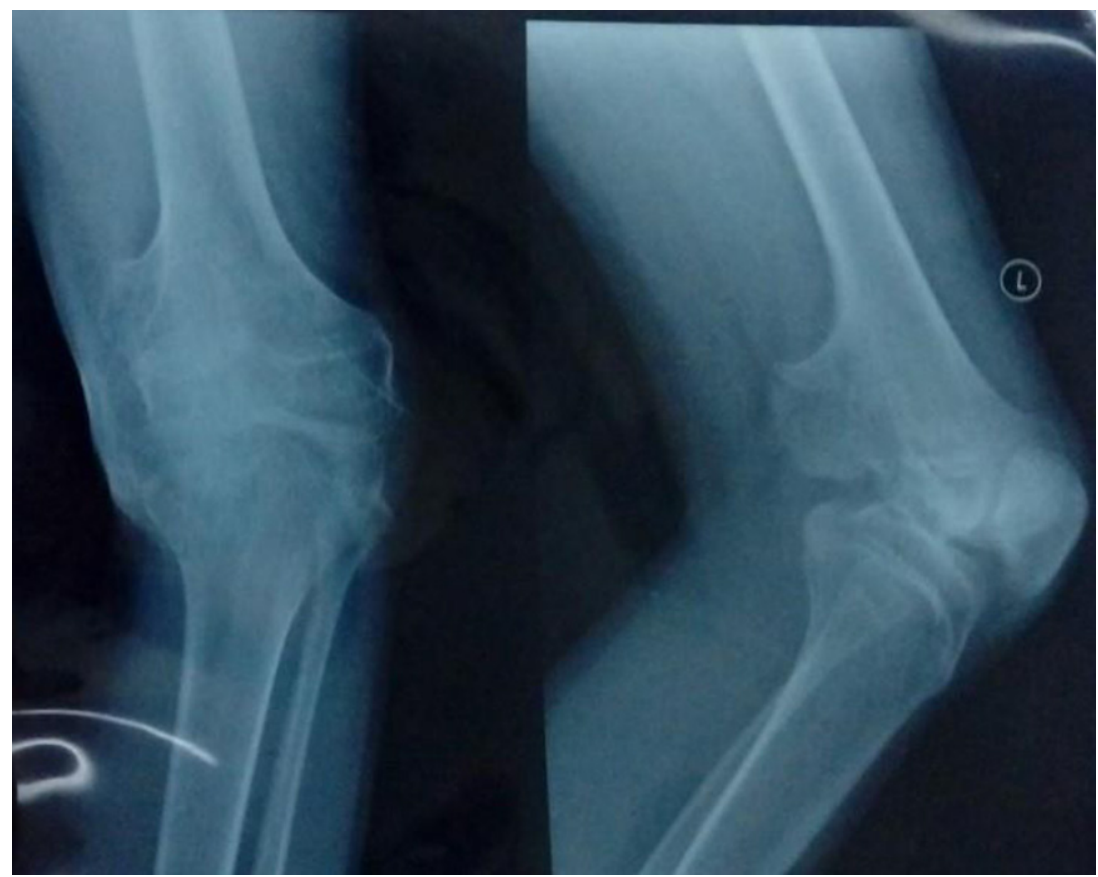

Figure 1. X-Ray examination before the surgical treatment

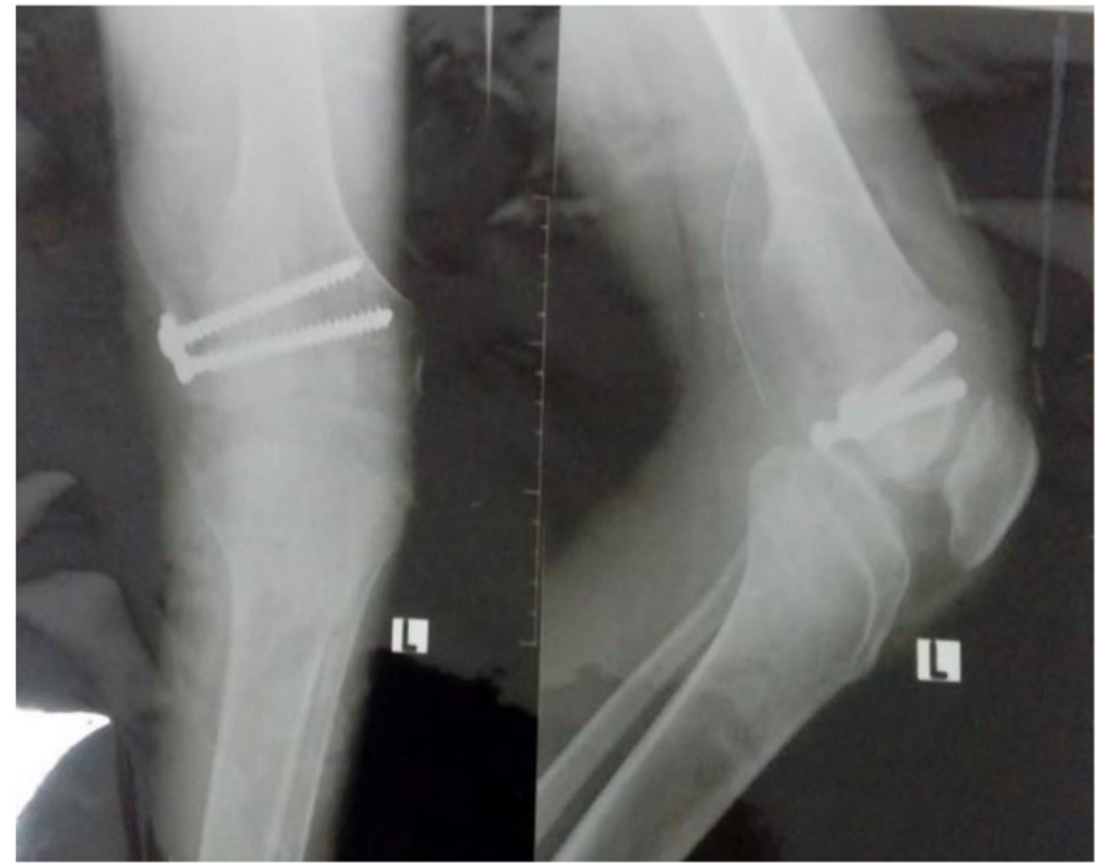

Figure 2. X-Ray examination after the surgical treatment cases with painless symptom. This case report aimed to describe the exercise program following surgical treatment in post-surgical release of knee flexion contracture in patient with osteochondroma. The patient had permitted to use this clinical case as a report.

\section{CASE DESCRIPTION}

In August 2019, a 16-year-old male high school student with left sided knee pain following a surgical release procedure was examined by physical therapist at the hospital. The pain has been lasting for three weeks along with limited movement on the left knee. He is the only child of his family, and the family history of having the same disease was denied.

Past medical history revealed that he had a motorbike accident that injured his left knee in December 2017. Right after the accident, he received wound management and suturing in the hospital. He felt persistent pain followed by an inability to extend his left knee. During past years, he took traditional massage therapy to relieved his condition. There was no improvement in his pain and his pain got worse when he was moving or resting. In June 2019, the patient went to local hospital to have radiological examination for his left knee. The radiology image showed abnormal bone exostosis on his distal femur (Figure 1). Then, he was referred to an orthopedic surgeon to receive surgical excision procedure for further management and evaluation.

On August 5, 2019, he received surgical procedure to release the knee flexion contracture. The surgical incision technique used a medial parapatellar capsular approach to the knee, followed by reconstruction procedure using 2 screws. The radiological images after surgical corrections are shown in Figure 2.

One day after surgery, the physical therapist inspected the general condition of the patient's limbs, while assessing the pain level and range of motions of the surgical area on the left knee. Inspection of the current condition (after three weeks) showed that the patient was able to walk independently with crutch and the surgical area was bandaged. The physical therapist loosed the bandage for further examination and found a painless mass and suspected muscle atrophy on the operated leg. There was no abnormality seen on the non-operated leg (right leg).

The knee joint range of motion was evaluated using a goniometer by asking the patient to actively perform knee flexion and extension. Limited knee range of motion with pain was found on the 
operated leg when compared with the non-operated leg. The hip joint and ankle joint mobility was also assessed by instructing the patient to actively perform all positions simultaneously. Mild pain on the operated leg was elicited by ankle dorsal flexion.

Manual muscle testing (MMT) was used to observe the leg muscle strength by instructing the patient to actively lift up both legs against the gravity one by one, started from the non-operated leg followed by the operated leg. The MMT score for the non-operated and operated legs were 4 and 3, respectively. Muscle atrophy was evaluated using tape measurement to assess the segment circumference from tibial tuberosity point. The segment circumference of the operated leg was found $3-5 \mathrm{~cm}$ smaller than the non-operated leg. Supporting examination using histopathology assessment was performed one day after the surgical procedure. The histopathology result referred to the characteristics of osteochondroma and chronic inflammation.

The physical therapy management was performed to improve the range of motion and muscles strength post-surgery and minimize the potential problem. A summary of the physical therapy interventions performed in this report can be seen in Table 1. After the interventions, the bandage was applied back on the operated leg. The exercise program was hold for three times in a week without any changes in the management procedures.

\section{Evaluation}

The patient was managed by a multidisciplinary team, which periodically assess the surgical site

Table 1. Physical therapy interventions

\begin{tabular}{|c|c|c|c|c|c|c|}
\hline Indication & Treatment site & $\begin{array}{l}\text { Physical therapy } \\
\text { intervention }\end{array}$ & Position & Procedure & Repetition & Equipment \\
\hline General weakness & Operated leg & $\begin{array}{l}\text { Strengthening } \\
\text { exercise: } \\
\text { Quadriceps } \\
\text { setting }\end{array}$ & Supine & $\begin{array}{l}\text { Maximally extended the } \\
\text { knee, then contracted the } \\
\text { muscles on top of his thigh } \\
\text { by pressing the back of } \\
\text { knee flat down while hold } \\
\text { up the knee for } 5 \text { seconds, } \\
\text { and slowly returned to the } \\
\text { starting position. }\end{array}$ & $\begin{array}{l}5-10 \text { times } \\
\text { as tolerated }\end{array}$ & Nil \\
\hline General weakness & Non-operated leg & $\begin{array}{l}\text { Strengthening } \\
\text { exercise: } \\
\text { Straight leg raise } \\
\text { 1. Hip flexion } \\
\text { 2. Hip abduction } \\
\text { 3. Hip extension } \\
\text { 4. Hip adduction }\end{array}$ & $\begin{array}{l}\text { 1. Supine } \\
\text { 2. Side-lying } \\
\text { 3. Prone } \\
\text { 4. Side-lying }\end{array}$ & $\begin{array}{l}\text { The patient performed } \\
\text { the exercise in which he } \\
\text { straightened his knee and } \\
\text { slowly lifted his leg, then } \\
\text { hold it for } 5 \text { seconds. }\end{array}$ & $\begin{array}{l}\text { 5-10 } \\
\text { repetitions }\end{array}$ & Nil \\
\hline $\begin{array}{l}\text { Potential } \\
\text { reduction of spinal } \\
\text { stabilization }\end{array}$ & Trunk muscle & $\begin{array}{l}\text { Dynamic stability } \\
\text { exercise: } \\
\text { Single leg bridge } \\
\text { exercise }\end{array}$ & Supine & $\begin{array}{l}\text { The non-operated leg was } \\
\text { fixed on the ground which } \\
\text { the heel was closed to the } \\
\text { glutes. The patient lifted } \\
\text { the left lower extremity and } \\
\text { pelvic while maintaining the } \\
\text { left hip in neutral position }\end{array}$ & $\begin{array}{c}5 \\
\text { repetitions, } \\
5 \text { seconds } \\
\text { each }\end{array}$ & Nil \\
\hline $\begin{array}{l}\text { Restriction of knee } \\
\text { joint mobility; } \\
\text { and Sensation of } \\
\text { muscle tightness }\end{array}$ & Operated leg & $\begin{array}{l}\text { Active-assisted } \\
\text { exercise }\end{array}$ & Sitting & $\begin{array}{l}\text { The patient changed to } \\
\text { sitting position on the edge } \\
\text { of the bed, while performing } \\
\text { knee flexion-extension on } \\
\text { the operated leg }\end{array}$ & $\begin{array}{l}\text { 5-10 } \\
\text { repetitions }\end{array}$ & Nil \\
\hline $\begin{array}{l}\text { Local } \\
\text { inflammation }\end{array}$ & Operated leg & Cryotherapy & Sitting & $\begin{array}{l}\text { The patient sat on bed with } \\
\text { the back support, and the } \\
\text { modality was given for } 5 \\
\text { minutes around the operated } \\
\text { area }\end{array}$ & $\begin{array}{l}\text { Once-daily } \\
\text { after all } \\
\text { exercises } \\
\text { were } \\
\text { performed }\end{array}$ & $\begin{array}{c}\text { Cold } \\
\text { modality }\end{array}$ \\
\hline
\end{tabular}


and signs of infection, bone growth and other complications. The patient was instructed to take the medicine routinely as directed by the physician in charge, and was given wound care management periodically. After three sessions of physical therapy management, the patient reported improvement in knee joint range of motion. However, the MMT on the operated leg was still the same, and the patient was still walking with a crutch. Outcomes were measured at initial examination, the second session, and the third session. Table 2 provides a summary of these findings.

Radiographic evaluation had not documented because of the short period of observation, and would be done after three months of follow-up. Therefore, the risks of malignant transformation of osteochondroma and other complications could not be evaluated in this report.

\section{DISCUSSION}

Knee flexion contracture can occur suddenly and significantly interfere with daily activities due to pain and limited movement. ${ }^{2}$ This symptom is a result of long period of immobilization and some complications, such as fracture, bone deformity, or mechanical joint problem that might be caused by oncologic problem. Osteochondroma is one of benign bone tumor that mostly found in male population. This tumor is usually symptomless and the diagnosis procedure is done by using radiological and histological examinations. ${ }^{4}$

Table 2. Outcome measures at baseline and at the second and third session

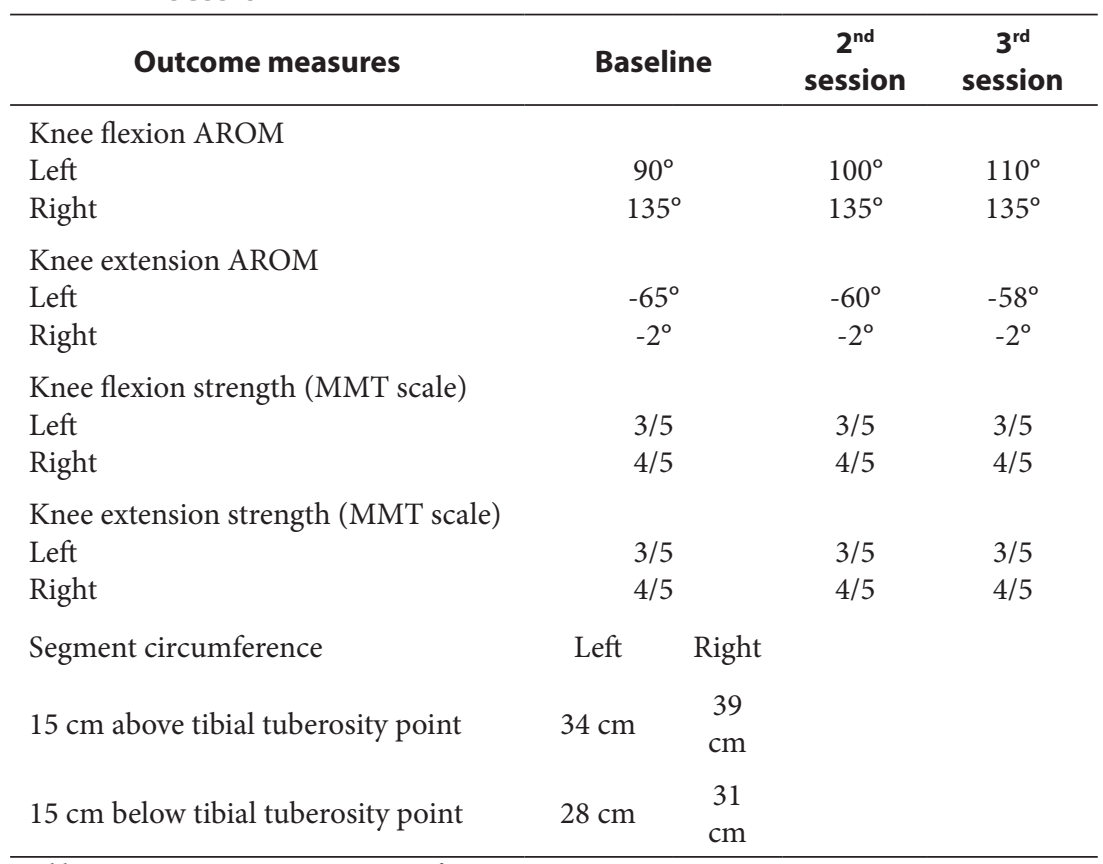

Abbreviations: AROM, active range of motion
Several cases of flexion deformity (limited extension) had been known to induce anterior impingement, contracture of anterior cruciate ligament (ACL) and posterior cruciate ligament (PCL), and contracture of the posterior joint capsule over the condyles and gastrocnemius muscles. Contracture of gastrocnemius muscle can be detected during the clinical examination by looking for a change in the flexion deformity when the ankle is moved to maximal dorsiflexion position.

Therefore, therehabilitationshouldbeundertaken right away by doing active mobilization, extension postures (several hours per day, as tolerated), and repeated static quadriceps contractions. ${ }^{9}$ The purpose of the active mobilization is to develop neuromuscular control, muscle endurance and strength. Long term muscles immobilization would result in physical stress reduction that further causes contractile protein shedding, decreases muscle fiber diameter, decreases the number of myofibrils and intramuscular capillary density, and finally results in muscle atrophy and weakness. ${ }^{1}$

Other research suggested the aim of postsurgical treatment is to recover basic lower limb functions, such as gait, knee mobility, and quadriceps strength. These active exercises have focus on the degrees of extension, because knee extension is usually required for everyday activities (e.g., standing, walking). However, approximately $117^{\circ}$ of knee flexion is necessary for some activities, such as squatting to tie a shoelace, pulling on a sock, or do prayer (shalat). Other activities, such as sitting in a chair requires approximately $90^{\circ}$ of flexion, and climbing stairs (average height) requires approximately $80^{\circ}$ of flexion. ${ }^{10,11}$

Based on the examination result, the patient reached the minimum range of motion for knee flexion which required to sitting in a chair and climbing stairs, even though the full knee extension was still hard to reached. The limitation of knee extension, significant kinematic changes on the trunk occurred. Limited during knee flexion commonly impacts the three-dimensional trunk kinematics during relaxed standing and level walking and will lead to spinal imbalance. The previous study has shown that the influence on the trunk kinematics depends on the severity of the knee flexion contracture. The results suggest that a flexion contracture of less than $15^{\circ}$ would not cause any adverse effect to the trunk. ${ }^{12}$ Therefore, we also gave instruction for the patient in this case to perform bridge exercise with single leg support which is known included in spine stabilization programs as a means to improve motor control and trunk muscle co-activation patterns for spine 
stabilization, and minimize the potential problem including spinal deformity. ${ }^{13} \mathrm{After}$ all active exercises were performed, cryotherapy is used because of its well documented local physiological responses of decreased temperature, metabolism, inflammation, circulation, pain, and muscle spasm. ${ }^{14}$

In current case report, ankle pain associated with patient's ankle movements was observed. The pathophysiology of ankle pain is related to the anatomical structures in which the gastrocnemius muscle crosses the posterior knee and both plantar, so that dorsiflexion could cause upward movement of the fibula and apply more stress to the ligaments supporting the superior tibiofibular joint. Otherwise, the plantar flexion would decrease the stress on these ligaments and also bring the gastrocnemius to support the posterior knee and assist the knee flexion. ${ }^{11}$

Furthermore, as osteochondroma does not develop after skeletal maturation, any new signs of growth observed through imaging or recent pain at bony lesions sites should be investigated for malignant potential. The change in metabolic activity and tumor size enlargement, accompanied by tumor margins irregularity and cap thickness more than $2 \mathrm{~cm}$ in adults and $3 \mathrm{~cm}$ in children are the signs of malignant transformation., ${ }^{2,4}$

Several limitations in our case report including inability to perform long term patient follow up are affected by limited time and opportunity, and lack of documentation on physical therapy management on the first day after surgery that result in inadequate evaluation report on patient intervention and outcome. Finally, our exercise program might benefit to reduce the muscle contracture and improve the knee joint range of motion in patient with osteochondroma following surgical release procedure. Further research with a larger group of patients with long-term evaluation is necessary to evaluate the safety and efficiency of exercise program in this case.

\section{CONFLICT OF INTEREST}

No commercial party having an interest in the subject matter of this research will give a benefit on the authors or on any affiliation with which the authors are associated.

\section{ACKNOWLEDGEMENT}

The authors want to thank the Dr. Soeharso Orthopedic Hospital in Solo and Bachelor and Professional Program of Physical Therapy, Udayana University in Bali, Indonesia for the clinical experience during internship program. This work received no funding from any institution.

\section{AUTHOR CONTRIBUTION}

DNM conceived the study design and data collection and drafted the manuscript; IK drafted the manuscript.

\section{REFERENCES}

1. Kisner C, Colby LA. Therapeutic Exercise: Foundations and Techniques. $6^{\text {th }}$ ed. Philadelphia: F.A. Davis Company; 2012.

2. Andrews K, Rowland A, Tank J. Knee Locked in Flexion: Incarcerated Semitendinosus Tendon around A Proximal Tibial Osteochondroma. Journal of Surgical Case Reports. 2019;2: 1-4

3. Khurana J, Abdul-Karin F, Bovée JVMG. Osteochondroma from World Health Organization Classification of Tumours: Pathology and Genetics of Tumours of Soft Tissue and Bone. International Agency for Research on Cancer. 2002; 234-236

4. Kitsoulis P, Galani V, Stefanaki K, Paraskevas G, Karatzias G, Agnantis NJ, Bai M. Osteochondromas: Review of the Clinical, Radiological and Pathological Features. In Vivo. 2008;5: 633-646

5. Mavrogenis A, Papagelopoulos P, Soucacos P. Skeletal Osteochondromas Revisited. Orthopedics. 2008;31(10): 1018-1028

6. Ng VY, Louie P, Punt S, Conrad EU. Surgical Release of Severe Flexion Contracture for Oncologic Knee Arthroplasty. The Open Orthopaedics Journal. 2017;11: 45-50

7. Miah A, Chu JS, Yegorov A. Post-Traumatic Osteochondroma of the Distal Femur. Radiology Case Reports. 2018;13: 208-211

8. Kim, TB, Kumar RJ, Gilrain KL, Kubat E, Devlin C, Honeywell S, Anin, SJ, Gutowski CJ. Team Approach: Rehabilitation Strategies for Patients After Osteosarcoma Reconstructive Surgery. Journal of Bone and Joint Surgery. 2020;8(10): 1-10

9. Pujol N, Boisrenoult P, Beaufils P. Post-Traumatic Knee Stiffness: Surgical Techniques. Orthopaedics and Traumatology: Surgery and Research. 2015;101: S179-S186

10. Morri M, Forni C, Ruisi R, Giamboi T, Giacomella F, Donati DM, Benedetti MG. Postoperative Function Recovery in Patients with Endoprosthetic Knee Replacement for Bone Tumour: an Observational Study. BMC Musculoskeletal Disorders. 2018;19(353): 1-7

11. Magee DJ. Orthopedic Physical Assessment. $6^{\text {th }}$ ed. Canada: Elsevier; 2014.

12. Harato $\mathrm{K}$, Nagura $\mathrm{T}$, Matsumoto $\mathrm{H}$, Otani $\mathrm{T}$, Toyama Y, Suda Y. A Gait Analysis of Simulated Knee Flexion Contracture to Elucidate Knee-Spine Syndrome. Gait and Posture. 2008; 28: 687-692

13. Garcia-Vaquero MP, Moreside JM, Brontons-Gil E, PecoGonzálesz N, Vera-Garcia FJ. Trunk Muscle Activation during Stabilization Exercises with Single and Double Leg Support. Journal of Electromyography and Kinesiology. 2012; 22: 398-406

14. Loro WA, Thelen MD, Rosenthal MD, Stoneman PD, Ross MD. The Effects of Cryotherapy on Quadriceps Electromyographic Activity and Isometric Strength in Patient in the Early Phases Following Knee Surgery. Journal of Orthopaedic Surgery. 2019; 27(1): 1-8

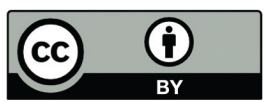

This work is licensed under a Creative Commons Attribution 